\title{
Comment on "Accentuation of Tumor Growth Secondary to Morphine Administration: The Proneoplastic Role of Morphine besides Its Role in Pain Management"
}

\author{
Shailendra Kapoor \\ 2300 E Cary Street, Richmond, VA 23111, USA \\ Correspondence should be addressed to Shailendra Kapoor, shailendrakapoor@yahoo.com
}

Received 23 February 2012; Accepted 27 March 2012

Copyright (c) 2012 Shailendra Kapoor. This is an open access article distributed under the Creative Commons Attribution License, which permits unrestricted use, distribution, and reproduction in any medium, provided the original work is properly cited.

I read with great interest the recent article by Luk et al. in a recent issue of your esteemed journal [1]. The article is highly thought provoking. Interestingly, the past few years have clearly revealed the connection between morphine administration and tumor development and progression.

For instance, morphine acts on the $\mu$-opioid receptors and increases intracellular cyclin D1 and activates G protein receptors resulting in accentuation of the mitogen-activated protein kinase (MAPK) pathway and thereby enhances angiogenesis in breast tumor cells [2]. In fact Farooqui et al. have recently demonstrated that morphine administration in breast tumor animal models activates prostaglandin $E_{2}$ thereby enhancing tumor metastasis also. Similar effects are noted in prostate cancer tissue [3]. For instance, patients who undergo radical prostatectomy for prostate carcinoma and who receive opioid treatment in conjunction with general anesthesia have a $57 \%$ higher risk of tumor recurrence in comparison to patients who receive general anesthesia in conjunction with epidural anesthesia [4]. Similarly, Mathew et al. have shown that morphine administration enhances tumor growth in lung cancer models [5].

Interestingly, methylnaltrexone inhibits activation of RhoA by inhibiting transactivation of VEGF receptors [6]. As a result it attenuates morphine-induced angiogenesis and thus inhibits tumor growth. PD98059 is another new agent that inhibits the MAPK pathway and thereby decreases opioid-induced tumor cell proliferation [7]. Similarly, celecoxib attenuates opioid-induced stimulation of cyclooxygenase- 2 receptors and thereby exerts antineoplastic effects [3].

These examples clearly illustrate the role of morphine in enhancing tumor angiogenesis and growth. Clearly, there is a further need to identify further such opioid receptor antagonists besides methylnaltrexone that can inhibit morphinemediated carcinogenesis.

\section{References}

[1] K. Luk, S. Boatman, and K. N. Johnson, "Influence of morphine on pericyte-endothelial interaction:implications for antiangiogenic therapy," Journal of Oncology, vol. 2012, Article ID 458385, 10 pages, 2012.

[2] K. Gupta, S. Kshirsagar, L. Chang et al., "Morphine stimulates angiogenesis by activating proangiogenic and survivalpromoting signaling and promotes breast tumor growth," Cancer Research, vol. 62, no. 15, pp. 4491-4498, 2002.

[3] M. Farooqui, Y. Li, T. Rogers et al., "COX-2 inhibitor celecoxib prevents chronic morphine-induced promotion of angiogenesis, tumour growth, metastasis and mortality, without compromising analgesia," British Journal of Cancer, vol. 97, no. 11, pp. 1523-1531, 2007.

[4] B. Biki, E. Mascha, D. C. Moriarty, J. M. Fitzpatrick, D. I. Sessler, and D. J. Buggy, "Anesthetic technique for radical prostatectomy surgery affects cancer recurrence: a retrospective analysis," Anesthesiology, vol. 109, no. 2, pp. 180-187, 2008.

[5] B. Mathew, F. E. Lennon, J. Siegler et al., "The novel role of the mu opioid receptor in lung cancer progression: a laboratory investigation," Anesthesia and Analgesia, vol. 112, no. 3, pp. 558567, 2011.

[6] P. A. Singleton, M. W. Lingen, M. J. Fekete, J. G. N. Garcia, and J. Moss, "Methylnaltrexone inhibits opiate and VEGF-induced angiogenesis: role of receptor transactivation," Microvascular Research, vol. 72, no. 1-2, pp. 3-11, 2006.

[7] S. Leo, R. Nuydens, and T. F. Meert, "Opioid-induced proliferation of vascular endothelial cells," Journal of Pain Research, vol. 2, pp. 59-66, 2009. 


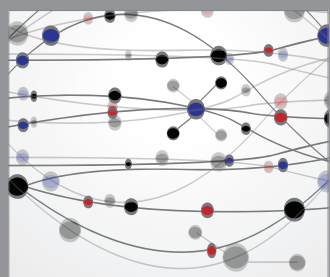

The Scientific World Journal
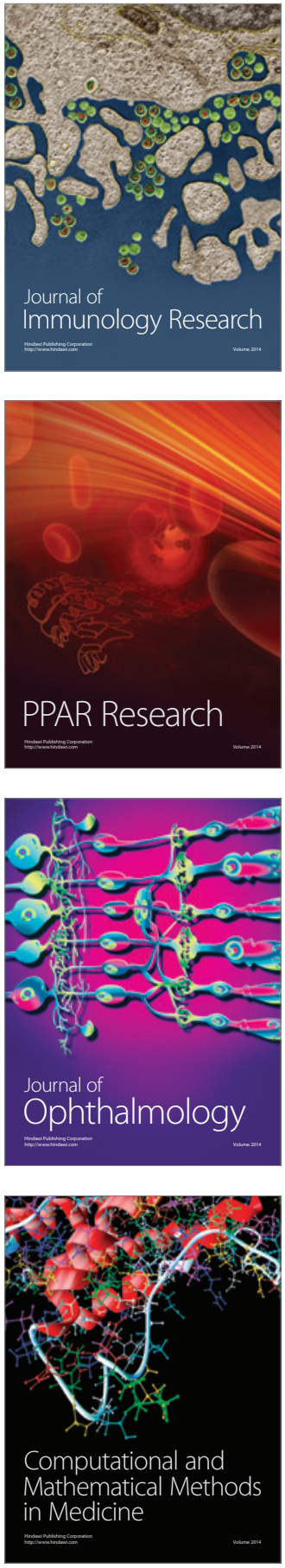

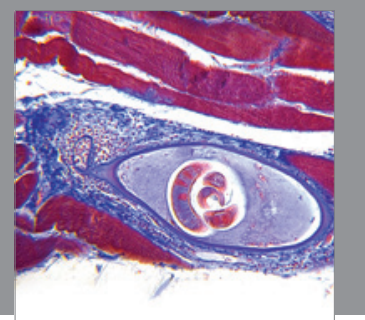

Gastroenterology

Research and Practice
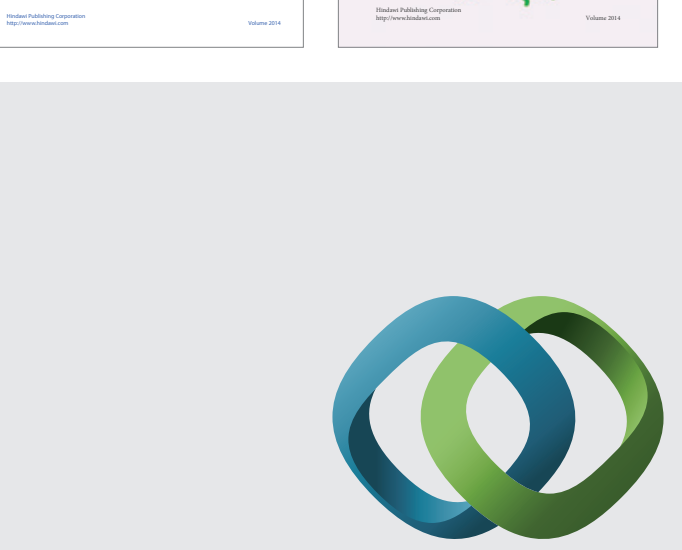

\section{Hindawi}

Submit your manuscripts at

http://www.hindawi.com
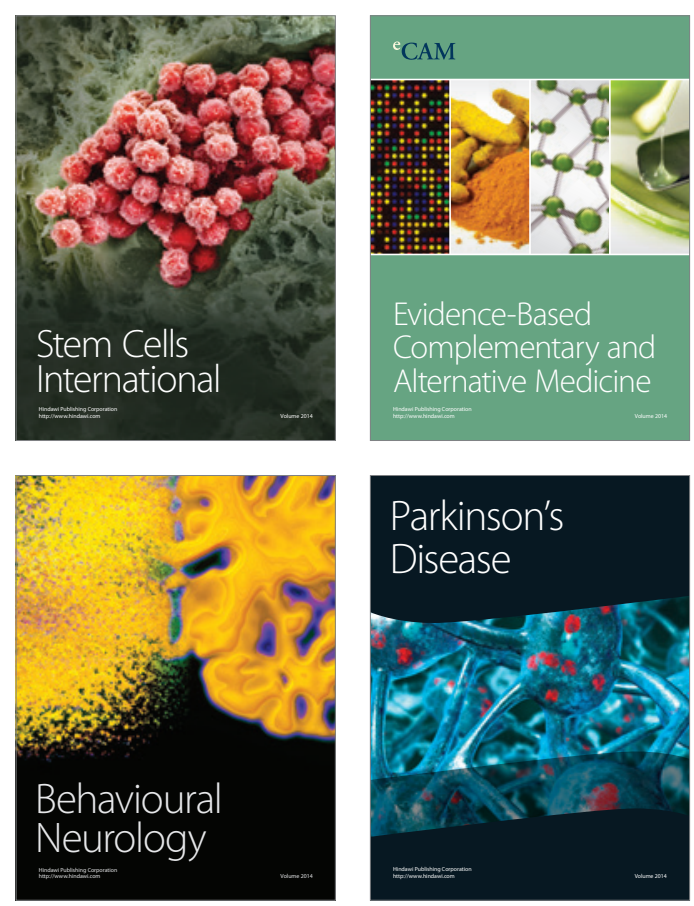

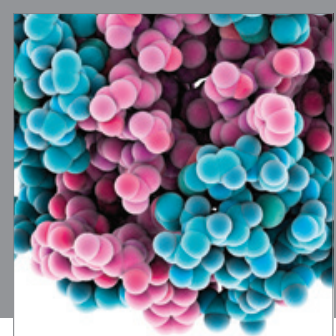

Journal of
Diabetes Research

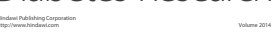

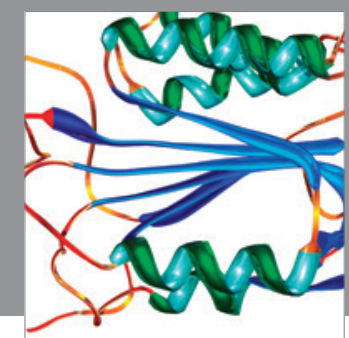

Disease Markers
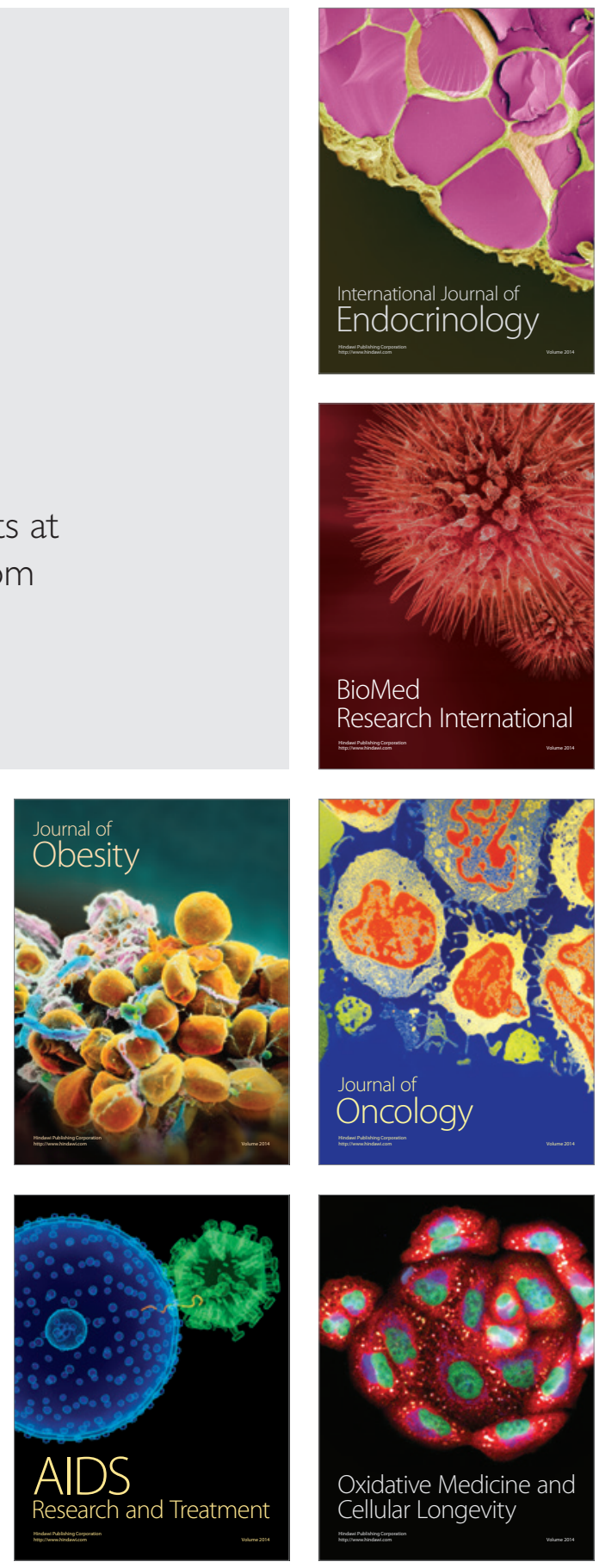